\title{
Groundwater Exploitation and Illegal Behaviors in a Differential Game
}

\author{
Marta Biancardi ${ }^{1}$. Gianluca lannucci ${ }^{2}$ (D) $\cdot$ Giovanni Villani $^{1}$
}

Accepted: 1 February 2022 / Published online: 21 February 2022

(c) The Author(s) 2022

\begin{abstract}
This paper studies groundwater management through a leader-follower differential game between a water agency and farmers. The access to the common pool is not free and farmers have to pay a water tax to withdraw. To save this cost, we assume that farmers may not declare all the water pumped and face the risk of being sanctioned. The water agency, on the other hand, knows that unauthorized water extraction may occur and chooses the water tax that maximizes only the legal social welfare. The value of the farmers' evasion share is unknown ex-ante by the water agency. The game is solved using feedback Nash solution. To understand how the water agency may counter illegal behaviors, we perform numerical simulations based on the Western La Mancha (Spain) aquifer data. It emerges that the optimal path of the water table is always above the minimum level, although it is sensitive to the level of the ecosystem costs. Moreover, increasing the administrative sanction reduces the unauthorized water extraction and raises the social welfare.
\end{abstract}

Keywords Leader-follower differential game · Groundwater management · Unauthorized water extraction $\cdot$ Feedback solution

\section{Introduction}

As a common-pool resource, all over the world water is pumped from beneath the ground faster than it is being replenished through rainfall. Moreover, the problem of groundwater exploitation is often accompanied by the phenomenon of unauthorized extraction. This occurs in many areas of the world, especially in arid regions or in areas experiencing population growth [10], both in developed and developing countries. For instance, in Western La Mancha region, according to [17], half of all firms may pump in an illegal way. A similar share of

This article is part of the topical collection"Dynamic Games in Environmental Economics andManagement" edited by Florian Wagener and Ngo Van Long.

Gianluca Iannucci

gianluca.iannucci@unifi.it

1 Department of Economics and Finance, University of Bari, Bari, Italy

2 Department of Economics and Management, University of Firenze, Via delle Pandette 9, I-50127 Florence, Italy 
illegal pumping is estimated also in Chile, according to the work of [6]. Non-compliant behaviors occur also in the USA [7]. These illegal practices could enhance the groundwater exploitation since the water agency interventions are less efficient.

The economic rationale for groundwater management has been widely questioned since the seminal work of [14]. They estimate that welfare gains from policy intervention are inefficient compared with competitive outcomes. Gisser and Sanchez's theoretical prediction is that if the storage capacity of the aquifer is relatively large, then the two systems would be very close. These results have produced an extensive literature about groundwater management (cf., [16]).

Among game theory approaches, the widely used is the dynamic one, in particular the differential game. [18] determines open-loop and feedback Nash solutions showing that the open-loop equilibrium captures only the pumping cost externality; however, in the feedback approach, the strategic externality also emerges. Moreover, if the objective function of the problem is concave, [23] show that the feedback solution increases in inefficiency with respect to the socially optimal outcome. Starting from [14] model, [25, 26] propose a differential game and determine analytical solutions of both open-loop and feedback scenarios over an infinite planning horizon. Their results are in line with ones of [14] and [18]. Indeed, they show that strategic behavior increases the exploitation of the aquifer compared with the openloop solution, but if the groundwater storage capacity is large, then the difference between the social optimum and private extraction is negligible. [12] introduce ecosystem damages showing that these environmental externalities can change the results substantially. [3] consider heterogeneous farmers in terms of behavior, cooperators and outsiders, in the exploitation of the water resource. Finally, [4] determine the efficient extraction of groundwater among overlapping generations.

However, the problem of illegal behaviors has been investigated mostly related to tradable permits (see, among others, [1, 27, 29]) and particularly in fisheries (see, among others, $[8,15]) .{ }^{1}$ Otherwise, to our knowledge, only few papers deal with illegal water extraction, namely $[2,5]$. In both papers the population of farmers is composed of two types, compliant and non-compliant, and are studied in two different contexts, differential game the first, evolutionary game the second. In this model, instead, we assume a population of identical farmers that choose an evasion share since they can adopt illegal behaviors not declaring all the water pumped. Moreover, here the water agency is a player of the game.

The aim of this paper is to investigate how the interaction between farmers and the water agency may arise illegal behaviors and how to counter them. For this purpose, we present a leader-follower differential game, where the water agency is the leader and the farmers are the follower. The last ones maximize profits myopically without considering the effects of their choices on the water table elevation. The water agency chooses the water tax that maximizes the social welfare under constraint of the water table dynamics. Differently from other papers, on the subject of groundwater management, we assume that the water agency knows the existence of non-compliant behaviors and, therefore, it maximizes only the legal net benefits. Related to this novelty, we assume that the farmers, to save on tax cost, may decide not to declare all the water pumped and face the risk of being sanctioned by the water agency. However, the water agency does not know ex-ante the value of the farmers' evasion share and so it is exogenously given in the inter-temporal maximization problem. The game is solved by feedback Nash solution, and we derive policy implications performing numerical simulations using real data from Western La Mancha aquifer. It emerges that the

1 Differently from these models that are analyzed in a static context, we propose a dynamic game between farmers and the water agency. This approach is widely used in the resource economics literature (cf., [28]). 
water table at the steady state is always above its minimum level and the pattern is sensitive to the value of the ecosystem costs. Moreover, if the sanction increases, the non-complaint water withdrawn decreases and the social welfare increases. However, the water table falls (although it remains above the minimum level).

The paper is organized as follows. Section 2 presents the problem of the farmers and the water agency, and Sect. 3 determines the feedback equilibrium and the evolution of groundwater level. Section 4 proposes numerical simulations about the effects of policy instruments and Sect. 5 concludes.

\section{The Model}

Let us consider a group of $N$ identical farmers that share a common groundwater resource. According to $[14,25]$, the demand for irrigation water is a negatively sloped linear function:

$$
W=\alpha-\beta p
$$

where $W \geq 0$ is the total water pumped, $\alpha>0$ is the intercept, $-\beta$ is the slope, with $\beta>0$, and $p$ is the price. Assuming competitive markets and symmetry between farmers it occurs that $W=w N$. Therefore, integrating the water price, we obtain the firm's level revenues:

$$
\int p(w) \mathrm{d} w=\frac{\alpha}{\beta} w-\frac{N}{2 \beta} w^{2}
$$

The total cost of extraction is a function of both water pumped $w$ and water table $H$ :

$$
C(w, H)=\left(c_{0}-c_{1} H\right) w
$$

where $c_{0}>0$ is the maximum average cost of extraction and $c_{1}>0$ is the marginal pumping cost with respect to the level of aquifer $H$ [25]. The ratio $\bar{H}=\frac{c_{0}}{c_{1}}$ represents the maximum water table elevation (the level of the groundwater in absence of exploitation). The right of pumping water for irrigation is given by the water agency after paying a $\operatorname{tax} \tau \geq 0\left(€ / \mathrm{Mm}^{3}\right)$ on individual withdrawals (cf., [11,24]). To save the tax cost, a farmer could not declare all the water pumped, choosing an evasion share $\theta \in[0,1]$ and facing the risk of being sanctioned by the water agency. Therefore, $(1-\theta) w$ is the amount of water pumped legally, while $\theta w$ represents the amount of water pumped illegally. The profit function is the following:

$$
\max _{\theta(t), w(t)} \Pi=\int_{0}^{+\infty} \pi(\theta(t), w(t)) e^{-r t} \mathrm{~d} t
$$

where

$$
\pi=\frac{\alpha}{\beta} w(t)-\frac{N}{2 \beta} w^{2}(t)-\left(c_{0}-c_{1} H(t)\right) w(t)-(1-\theta(t)) \tau(t) w(t)-\phi \theta(t) \tau(t) \sigma w(t),
$$

$r \in(0,1)$ is the discount rate, $\phi \in(0,1]$ is the probability of being discovered by the water agency, and $\sigma>1$ is the administrative sanction. ${ }^{2}$ We assume that the probability of being

\footnotetext{
${ }^{2}$ In the real world, an example of multiplicative sanction is given by the California Cap and Trade System, in which $\sigma=4$ (see https://ww2.arb.ca.gov/resources/documents/faq-cap-and-trade-program). Differently, in the European Emission Trading System the sanction is additive, EUR 100/tCO $\left(\mathrm{USD} 114.22 / \mathrm{tCO}_{2}\right.$ ) for each ton of $\mathrm{CO}_{2}$ emitted for which no allowance has been surrendered, in addition to buying and surrendering the equivalent amount of allowances (see https://icapcarbonaction.com/en/?option=com_etsmap\&task=export\& format=pdf\&layout=list\&systems $\% 5 \mathrm{~B} \% 5 \mathrm{D}=43$ ).
} 
discovered is a function of the evasion share:

$$
\phi=\eta \theta(t)
$$

where $\eta \in(0,1]$ is a parameter that captures the monitoring effort of the water agency.

Differently from farmers, the water agency chooses the water tax in order to maximize the social welfare $(S W)$, composed of net benefits $(N B)$ and environmental damage $(E D)$, subject to the water table dynamics, composed of natural recharge $(R>0)$, farmers' pumping and natural discharge ${ }^{3}$ :

$$
\begin{aligned}
\max _{\tau(t)} S W & =\int_{0}^{+\infty}[N B(t)-E D(t)] e^{-r t} \mathrm{~d} t \\
\text { s.t. } \dot{H} & =[R-(1-\gamma) N w(t)-(H(t)-\widehat{H}) \delta] \frac{1}{S_{a}} \\
H(0) & =H_{0} \quad \text { and } H(t)>\widehat{H}
\end{aligned}
$$

where $S_{a}>0$ represents the aquifer area times storativity, $\gamma \in(0,1)$ is the return flow coefficient, $\delta>0$ represents the natural discharge parameter, $\widehat{H}$ refers to the minimum level of the water table for which the natural discharge is nil, and $H(0)=H_{0}$ is the initial value of $H$ at time $t=0$. The condition $H(t)>\widehat{H}$ is necessary to avoid environmental disasters. Indeed, suppose that the natural discharge of a such aquifer is an adjacent river. If $H(t)>\widehat{H}$, the water goes from the aquifer to the river. However, if $H(t)<\widehat{H}$, the water goes from the river to the aquifer, and this may have disastrous environmental consequences. For this reason, we assume that the water agency has as a constraint $H(t)>\widehat{H}$.

The water agency knows that the farmers could not declare all the water pumped, and, therefore, the net benefits are represented by only the legal net profits, namely the representative firm's profits that derive from pumping legal water without taxation and sanction times the number of firms $N$. Denoting with $w_{c}$ the compliant water withdrawn, we can define the net benefits as:

$$
N B(t)=\left[\frac{\alpha}{\beta} w_{c}(t)-\frac{N}{2 \beta} w_{c}^{2}(t)-\left(c_{0}-c_{1} H(t)\right) w_{c}(t)\right] N
$$

Since $w_{c}=(1-\theta(t)) w$, we can rewrite the net benefits as:

$$
N B(t)=\left[\frac{\alpha}{\beta} w(t)-\frac{N}{2 \beta}(1-\theta(t)) w^{2}(t)-\left(c_{0}-c_{1} H(t)\right) w(t)\right](1-\theta(t)) N
$$

Finally, the environmental damage is composed of two parts: the cost of capture, namely the ecosystem damages associated with consumptive uses [21], and the cost the ecosystem damages associated with non-consumptive uses [13]. Formally:

$$
E D(t)=[R-(H(t)-\widehat{H}) \delta] \lambda+(\bar{H}-H(t)) \mu
$$

where $\lambda>0$ and $\mu>0$. Following [22], we can rewrite the environmental damage as

$$
E D(t)=d_{0}-d_{1} H(t)
$$

where $d_{0}=(R+\Omega) \lambda+\mu \bar{H}, d_{1}=\delta \lambda+\mu$, and $\Omega=\delta \widehat{H}$.

3 The natural discharge can be a river or a groundwater-dependent ecosystem adjacent to the aquifer [19]. 


\section{The Differential Game}

The interaction between the water agency and the farmers is given by a leader-follower differential game, in which the water agency is the leader and the farmers play the role of the follower. The dynamics of the game is the following:

(1) the water agency announces the water tax;

(2) the farmers choose the optimal share of evasion $\theta$ and the optimal pumping level $w$ solving the problem (1);

(3) the water agency chooses the optimal water tax $\tau$ solving the problem (3) under the dynamics (4);

(4) adopting a feedback strategy, the water agency derives the steady-state value of the water table $H$.

The farmers, as follower, behave myopically maximizing profits without considering the impact of their decisions on the stock of water (see, for instance, [11,20]). The water agency, as leader, solves an optimal control problem determining the water tax throughout the planning horizon. Since the farmers hide their illegal behaviors, the water agency does not know exante the value of the evasion share $\theta$. Therefore, it is exogenously given in the maximization problem. The following propositions hold.

Proposition 1 Let

$$
\widetilde{H}=\max \left\{0,\left(c_{0}-\frac{\alpha}{\beta}\right) \frac{1}{c_{1}}\right\}
$$

and

$$
\bar{\tau}=\frac{\frac{\alpha}{\beta}-\left(c_{0}-c_{1} H\right)}{\eta \sigma}
$$

If $H \in[\tilde{H}, \bar{H}]$ and $\tau \in[0, \bar{\tau})$, then the optimal value of the water pumped is:

$$
\widetilde{w}=\left[\frac{\alpha}{\beta}-\left(c_{0}-c_{1} H(t)\right)-\left(1-\theta+\theta^{2} \eta \sigma\right) \tau(t)\right] \frac{\beta}{N}
$$

Otherwise, if $H \in[0, \widetilde{H})$ and $\tau \in[\bar{\tau},+\infty), \widetilde{w}=0$.

Proof See Mathematical Appendix.

Proposition 2 If $\eta \in\left[\frac{1}{2}, 1\right]$, the optimal value of the evasion share is:

$$
\widetilde{\theta}=\frac{1}{2 \eta \sigma}
$$

Otherwise, if $\eta \in\left(0, \frac{1}{2}\right), \widetilde{\theta}=1$.

Proof See Mathematical Appendix.

By Proposition 2 we can infer that the farmers are never fully compliant $(\widetilde{\theta}>0$ always $)$ and that if the monitoring effort $(\eta)$ is not sufficiently high then $\widetilde{\theta}=1$, namely the farmers are fully non-compliant. Moreover, $\widetilde{\theta}$ is time-invariant, since it is not a function neither of the control variable nor of the state variable. The threshold level $\widetilde{H}$ represents the farmers' zero water condition. As we are interesting when farmers pump a strictly positive amount of water and evade only a share of the water pumped, we assume from now that $\tau \in[0, \bar{\tau})$ and $\eta \in\left[\frac{1}{2}, 1\right]$. 
Substituting the value $\widetilde{w}$ given by (10) in (3) subject to dynamics (4) and $H \in[\underline{H}, \bar{H}]$ (where $\underline{H}=\min \{\widetilde{H}, \widehat{H}\}$ ), the Hamilton-Jacobi-Bellman (HJB) for the water agency follows:

$$
\begin{aligned}
r V(H, t)= & \max _{\tau}\left\{N(1-\theta)\left[\frac{\alpha}{\beta} \widetilde{w}-\frac{N}{2 \beta}(1-\theta) \widetilde{w}^{2}-\left(c_{0}-c_{1} H(t)\right) \widetilde{w}\right]\right. \\
& \left.-\left(d_{0}-d_{1} H(t)\right)+\frac{V^{\prime}(H, t)}{S_{a}}[R-(1-\gamma) \widetilde{w} N+\Omega-\delta H(t)]\right\}
\end{aligned}
$$

where $V(H, t)$ and $V^{\prime}(H, t)$ are the optimal control value function and its derivative with respect to the state variable $H$, respectively. The analysis of the model can be found in Mathematical Appendix. The following proposition holds.

Proposition 3 A unique steady state for the feedback equilibrium of the game exists:

$$
H^{*}=-\frac{Y}{\widehat{Y}}
$$

where

$$
Y=\frac{1}{S_{a}}\left\{R+\Omega+\frac{(1-\gamma) \eta \sigma\left[2 S_{a}\left(\beta c_{0}-\alpha\right)(2 \eta \sigma-1)+4 B_{1}(1-\gamma) \beta \eta \sigma\right]}{(2 \eta \sigma-1)^{2} S_{a}}\right\}
$$

and

$$
\widehat{Y}=-\frac{1}{S_{a}}\left\{\frac{\eta \sigma \beta(1-\gamma)\left[2(2 \eta \sigma-1) c_{1} S_{a}-8 A_{1}(1-\gamma) \eta \sigma\right]}{(2 \eta \sigma-1)^{2} S_{a}}+\delta\right\}
$$

The feedback equilibrium water table trajectory is given by:

$$
H(t)=H^{*}+\left(H_{0}-H^{*}\right) e^{\widehat{Y} t}
$$

where $H_{0}$ is the initial value of the water table.

Proof See Mathematical Appendix.

\section{Simulations and Policy Implications}

We perform now numerical simulations to derive some policy implications, in particular how to counter illegal behaviors. Parameter values used are from Western La Mancha aquifer and are shown in Table 1. These data are widely used in the literature (among others, [9, 12, 22]).

The first simulations, see Fig. 1, represent the optimal trajectories of water table $H$, water taxation $\tau$, social welfare $S W$ and total water pumped $W$, divided in compliant $\left(W_{c}=\right.$ $\left.(1-\widetilde{\theta}) N w^{*}\right)$ and non-compliant $\left(W_{b}=\widetilde{\theta} N w^{*}\right)$. In (6) we split the environmental damage in two parts: The ecosystem costs associated with consumptive uses, $[R-(H(t)-\widehat{H}) \delta] \lambda$, and the ecosystem costs associated with non-consumptive uses, $(\bar{H}-H(t)) \mu$. To better understand the impact of these monetary environmental costs on the dynamics of the model and considering that in the literature $\lambda \in[0,30000]$ and $\mu \in[0,50000]$, we perform simulations using three different values of $\lambda$ and $\mu$, low, medium and high, leaving constant the ratio between them. The initial condition is the maximum level of the aquifer $(665 \mathrm{~m}$, namely $\left.H_{0}=\bar{H}=c_{0} / c_{1}\right)$ that represents a world without human activity. Conversely, the minimum level to avoid ecosystem disasters is $\widehat{H}=600 \mathrm{~m}$. Finally, notice in Table 1 that $\widehat{H}>\widetilde{H}$. Therefore, the water tax is always positive and $H^{*} \in(\widehat{H}, \bar{H})$. 
Table 1 Parameter values

\begin{tabular}{llll}
\hline Parameters & Description & Units & Value \\
\hline$\alpha$ & Intercept of the water demand & $€ / \mathrm{Mm}^{3}$ & 4400.73 \\
$\beta$ & Slop of the water demand & $€ / \mathrm{Mm}^{3}$ & 0.097 \\
$c_{0}$ & Intercept of the pumping cost & $€ / \mathrm{Mm}^{3}$ & 266000 \\
$c_{1}$ & Slope of the pumping cost & $€ / \mathrm{Mm}^{3} m$ & 400 \\
$\gamma$ & Return flow coefficient & - & 0.2 \\
$S_{a}$ & Aquifer area & $\mathrm{Mm}^{2}$ & 126.5 \\
$R$ & Natural recharge & $M m^{3}$ & 360 \\
$\bar{H}$ & Maximum water level and initial condition & $m$ & 665 \\
$\widehat{H}$ & Minimum water level for nil natural discharge & $m$ & 600 \\
$\widetilde{H}$ & Minimum water level for nonnegative $\tau$ & $m$ & 551.5791 \\
$r$ & Discount rate & - & 0.02 \\
$\delta$ & Slope of the natural drainage & $€ / \mathrm{Mm}^{3}$ & 5.53 \\
$\eta$ & Monitoring effort & - & 0.8 \\
$\sigma$ & Administrative sanction & - & 2 \\
$N$ & Number of farmers & - & 50
\end{tabular}

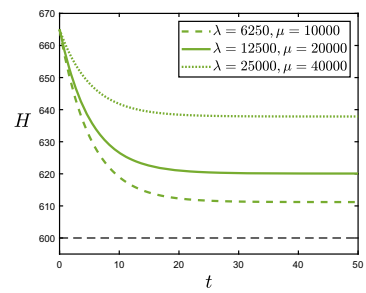

(a) Water table.

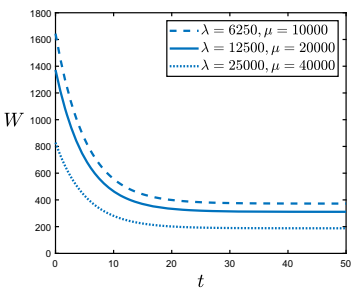

(d) Total water pumped.

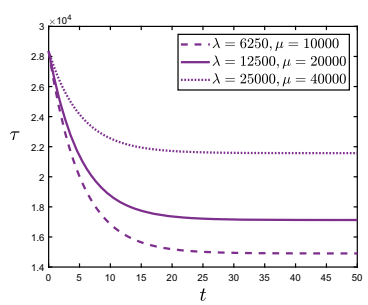

(b) Water tax.

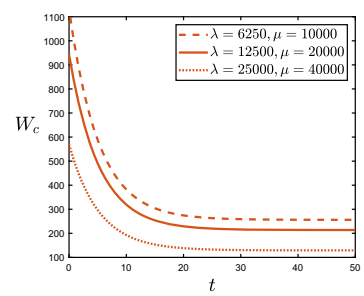

(e) Compliant water pumped.

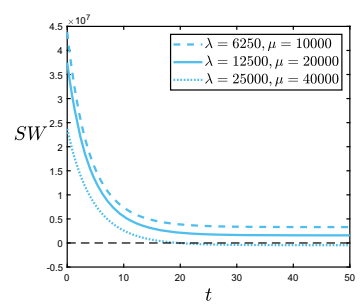

(c) Social welfare.

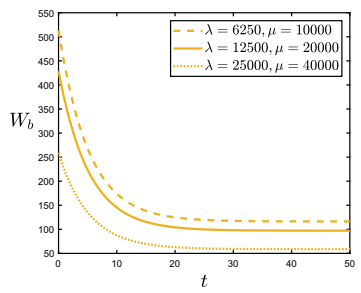

(f) Non-compliant water pumped.

Fig. 1 Optimal trajectories of $H, \tau, S W, W, W_{c}$ and $W_{b}$

As one may expect, since $H_{0}=\bar{H}$, the steady-state value of the water table is lower than the initial level, $H^{*}<H_{0}$, namely the water table decreases as time increases (see Fig. 1a). Notice that $H^{*}>\widehat{H}$ and so the natural recharge is sufficient to restore the aquifer. One of the consequence of a lower water table is higher pumping cost (remember that $C(w, H)=$ 
Table 2 Steady-state values

\begin{tabular}{llll}
\hline Function & $\lambda=6250, \mu=10000$ & $\lambda=12500, \mu=20000$ & $\lambda=25000, \mu=40000$ \\
\hline$H^{*}$ & $611.1922 \mathrm{~m}$ & $620.0834 \mathrm{~m}$ & $637.8667 \mathrm{~m}$ \\
$\tau^{*}$ & $14903.2668 € / \mathrm{Mm}^{3}$ & $17126.1465 € / \mathrm{Mm}^{3}$ & $21571.9059 € / \mathrm{Mm}^{3}$ \\
$S W^{*}$ & $3301227.6481 €$ & $1582331.7164 €$ & $-46183.7949 €$ \\
$W^{*}$ & $372.4941 \mathrm{Mm}^{3}$ & $310.9203 \mathrm{Mm}^{3}$ & $187.7729 \mathrm{Mm}^{3}$ \\
$W_{c}^{*}$ & $256.0897 \mathrm{Mm}^{3}$ & $213.7577 \mathrm{Mm}^{3}$ & $129.0938 \mathrm{Mm}^{3}$ \\
$W_{b}^{*}$ & $116.4044 \mathrm{Mm}^{3}$ & $97.1626 \mathrm{Mm}^{3}$ & $58.6790 \mathrm{Mm}^{3}$ \\
\hline
\end{tabular}

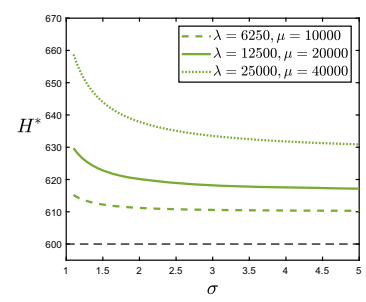

(a) Water table.

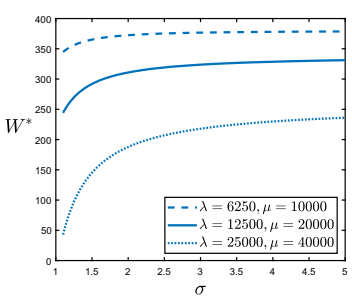

(d) Total water pumped.

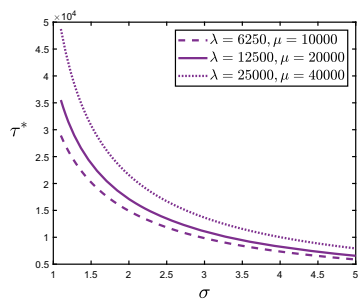

(b) Water tax.

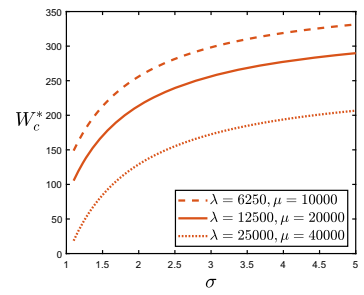

(e) Compliant water pumped.

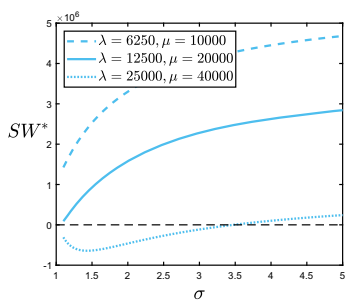

(c) Social welfare.

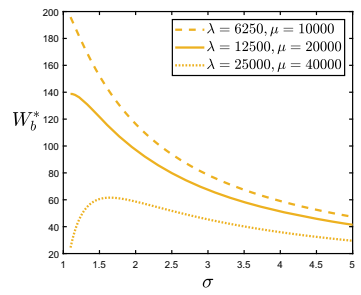

(f) Non-compliant water pumped.

Fig. 2 Comparative statics of $H, \tau, S W, W, W_{c}$ and $W_{b}$ at increasing values of the sanction $\sigma$ in the steady state

$\left.\left.\left(c_{0}-c_{1} H\right) w\right)\right)$ which can lead to a decrease of the total water pumped (see Fig. 1c). ${ }^{4}$ Since the water table level does not affect the optimal evasion share $\widetilde{\theta}$ (see (11)), then both the total compliant water $W_{c}$ and the total non-compliant water $W_{b}$ fall (see Fig. $1 \mathrm{~d}$ and e, respectively). Moreover, from the numerical simulations it emerges that $\tau$ decreases as time increases (see Fig. 1b). Finally, lower water withdrawn reduces both net benefits and environmental damage. However, the first effect prevails over the second one, and so the social welfare falls (see Fig. 1c).

Figure 1 shows also the importance of the monetary ecosystem costs $\lambda$ and $\mu$ in the computation of function values in the steady state (see also Table 2). If the ecosystem costs increases, then also the water tax increases, since $\tau$ reduces water pumping and hence the environmental damage preserving the water table. As consequence, the net benefits falls and the environmental damage increases, so the social welfare decreases. Notice that if the ecosystem costs are high, the social welfare can be even negative. Moreover, a higher tax

4 The relationship between $\tau$ and $H$ can be positive or negative depending on parameter values, especially on the magnitude of the marginal pumping $\operatorname{cost} c_{1}$ (a relatively lower $c_{1}$ causes a positive relation). 
means a higher water table that reduces the pumping costs. Taxes and level of the water table go in the same direction. A possible explanation of this phenomenon is that a drop in the water table increases pumping costs making water pumping less profitable. Therefore, the agency can soften the regulation by not imposing a large tax to control water pumping. Finally, lower pumping costs imply that the total water pumped increases, both compliant and non-compliant one.

We focus now on the contrast of illegal behaviors, performing a numerical comparative statics analysis in the steady state by changing the sanction $\sigma$. Obviously, if $\sigma$ increases, the optimal evasion share $\widetilde{\theta}$ decreases, and so $W_{c}^{*}$ raises while $W_{b}^{*}$ falls (see Fig. 2e and f, respectively). An increase of $W_{c}^{*}$ leads to an increase of net benefits (see (5)) and so social welfare raises (see Fig. 2c). Interestingly, from simulations it emerges that an increase of $\sigma$ causes a decrease of $\tau$ (see Fig. 2b). This leads to a rise of the total water pumped (see Fig. 2d) and, as consequence, a drop of the water table (see Fig. 2a).

Also in the comparative statics analysis, the increase of the monetary ecosystem costs causes an increase of the water tax $\tau^{*}$ and of the water table $H^{*}$. A higher tax means lower net benefits (and so, lower social welfare) but also lower water pumped. Since $\widetilde{\theta}$ is not a function of $\lambda$ and $\mu$, then the ecosystem costs have no effects on illegal behaviors. Finally, notice that if the sanction is low and the ecosystem costs are high, the social welfare is negative. This means that environmental damage outweighs legal profits and so to ensure a positive social welfare is necessary a relatively high sanction. Moreover, it is outlined a non-monotonically shape between sanction and social welfare as well as sanction and noncompliant water (always for relative low values of the sanction). This is particularly the case when monetary ecosystem costs are high and when social welfare is negative. Probably it happens because the sanction is not sufficiently high to ensure a positive social welfare (remember that it is composed of only legal profits). Such limit case may present incentives to be non-compliant also for increasing values of the sanction (but up to a certain point).

Summarizing, the sanction can reduce non-compliant behaviors and increase the social welfare. However, it has negative effects on the water table (higher sanction leads to lower aquifer level), although it remains above the minimum level.

\section{Conclusions}

Unauthorized water extraction is a phenomenon not yet satisfactorily investigated, in particular from a theoretical point of view. To fill this gap in the literature, we built a model in which the farmers, in order to save a tax on withdrawals, can evade a share of the water pumped facing the risk of being sanctioned. The water agency knows that non-compliant behaviors may arise and so its objective function is composed of only legal social welfare. (Profits derived from illegal water pumped are not maximized.) However, the water agency does not know ex-ante the value of the water evasion share, hidden by the farmers. The sequence of the game is the following: (1) the water agency announces the water taxation, (2) farmers choose the level of pumping and the share of evasion, (3) the water agency chooses the water taxation that maximizes the social welfare, (4) adopting a feedback strategy, the steady-state value of the water table is derived.

Numerical simulations, using Western La Mancha data, show that all the key functions of the model, such as water table, social welfare, taxation, and total water pumped (both compliant and non-compliant), are all decreasing over time. Moreover, the quantitative results are very sensitive to the monetary ecosystem costs associated with both consumptive and non- 
consumptive uses. Indeed, these costs increase the water table and the taxation while reduces the water pumped (both compliant and non-compliant) and so the social welfare (that could be negative if these costs are high and the sanction is relatively low).

In addition, to counter non-complaint behaviors, we perform a comparative statics analysis in the steady state changing the sanction level. It emerges that the sanction can reduce these unauthorized water extraction at the expense of lower water table (although it remains above the minimum level).

Acknowledgements We would like to thank the two anonymous reviewers whose comments and suggestions helped improve and clarify this manuscript.

Funding Not applicable.

\section{Declarations}

Conflict of interest The authors declare that they have no conflict of interest.

Open Access This article is licensed under a Creative Commons Attribution 4.0 International License, which permits use, sharing, adaptation, distribution and reproduction in any medium or format, as long as you give appropriate credit to the original author(s) and the source, provide a link to the Creative Commons licence, and indicate if changes were made. The images or other third party material in this article are included in the article's Creative Commons licence, unless indicated otherwise in a credit line to the material. If material is not included in the article's Creative Commons licence and your intended use is not permitted by statutory regulation or exceeds the permitted use, you will need to obtain permission directly from the copyright holder. To view a copy of this licence, visit http://creativecommons.org/licenses/by/4.0/.

\section{Mathematical Appendix}

\section{Proof of Proposition 1}

Substituting (2) in (1) and given the value of $\tau$ and $H$, the first order conditions with respect to water pumped are:

$$
\frac{\partial \pi}{\partial w}=\frac{\alpha}{\beta}-\frac{N}{\beta} w-c_{0}+c_{1} H-(1-\theta) \tau-\theta^{2} \eta \tau \sigma=0
$$

Solving, we get:

$$
w=\widetilde{w}:=\left[\frac{\alpha}{\beta}-\left(c_{0}-c_{1} H(t)\right)-\left(1-\theta+\theta^{2} \eta \sigma\right) \tau(t)\right] \frac{\beta}{N}
$$

Notice that $\widetilde{w}>0$ if and only if

$$
\tau<\frac{\frac{\alpha}{\beta}-\left(c_{0}-c_{1} H\right)}{1-\theta+\theta^{2} \eta \sigma}
$$

Since $\tau(\theta)$ is a continuous function over a closed and bounded interval $[0,1]$, then the extreme value theorem occurs. Differentiating, we obtain:

$$
\tau^{\prime}(\theta)=\frac{\left(\frac{\alpha}{\beta}-c_{0}+c_{1} H\right)(1-2 \theta \eta \sigma)}{\left(1-\theta+\theta^{2} \eta \sigma\right)^{2}}
$$


Equaling to zero, we get $\theta=\frac{1}{2 \eta \sigma}$. It occurs $\tau^{\prime}(\theta)>0$ for $\theta \in\left[0, \frac{1}{2 \eta \sigma}\right)$ and $\tau^{\prime}(\theta)<0$ for $\theta \in\left(\frac{1}{2 \eta \sigma}, 1\right]$. Therefore, $\theta=\frac{1}{2 \eta \sigma}$ is a maximum point. Moreover,

$$
\tau(0)=\frac{\alpha}{\beta}-\left(c_{0}-c_{1} H\right) \quad \text { and } \quad \tau(1)=\frac{\frac{\alpha}{\beta}-\left(c_{0}-c_{1} H\right)}{\eta \sigma}
$$

and so, $\tau(0)>\tau(1)$. Therefore, $\widetilde{w}>0 \forall \theta \in[0,1]$ if and only if

$$
\tau<\bar{\tau}:=\frac{\frac{\alpha}{\beta}-\left(c_{0}-c_{1} H\right)}{\eta \sigma}
$$

Moreover, notice that $\bar{\tau} \geq 0$ if and only if:

$$
H \geq \widetilde{H}:=\left(c_{0}-\frac{\alpha}{\beta}\right) \frac{1}{c_{1}}
$$

Therefore, $\tau \in[0, \bar{\tau})$ is a sufficient condition to ensure a strictly positive water pumped. If the condition $\tau<\bar{\tau}$ is not satisfied, then $w$ could be equal to zero, and so no water is pumped by the farmers.

\section{Proof of Proposition 2}

Substituting (2) in (1) and given the value of $\tau$ and $H$, the first order conditions with respect to evasion share are:

$$
\frac{\partial \pi}{\partial \theta}=\tau w-2 \theta \eta \tau \sigma w=0
$$

Solving, for $w \neq 0$ and $\tau \neq 0$, we obtain:

$$
\widetilde{\theta}=\frac{1}{2 \eta \sigma}
$$

Notice that $\widetilde{\theta}>0$ always, while $\widetilde{\theta} \leq 1$ if

$$
\eta \geq \frac{1}{2 \sigma}
$$

Since $\sigma>1$, then $\eta \in\left[\frac{1}{2}, 1\right]$ is a sufficient condition to ensure $\tilde{\theta} \in(0,1)$.

\section{Hamilton-Jacobi-Bellman System}

Assuming an interior solution and differentiating the right-side of equation (12) with respect to $\tau$, we lead:

$$
\tau=\frac{\theta\left[\left(c_{0}-c_{1} H(t)\right) \beta-\alpha\right]}{\beta(1-\theta)\left(1-\theta+\theta^{2} \eta \sigma\right)}+\frac{V^{\prime}(H, t)(1-\gamma)}{S_{a}(1-\theta)^{2}\left(1-\theta+\theta^{2} \eta \sigma\right)}
$$

Replacing $\widetilde{\theta}$ given by (11) in $\tau$ given by (17), we obtain:

$$
\tau=\eta \sigma\left\{\frac{4\left[\left(c_{0}-c_{1} H(t)\right) \beta-\alpha\right]}{(4 \eta \sigma-1) \beta(2 \eta \sigma-1)}+\frac{16 V^{\prime}(H, t)(1-\gamma) \sigma^{2} \eta^{2}}{(4 \eta \sigma-1) S_{a}(2 \eta \sigma-1)^{2}}\right\}
$$


Substituting $\tau$ given by (18) in $\widetilde{w}$ given by (10) and $\widetilde{\theta}$ given by (11), we have:

$$
w=-\eta \sigma\left\{\frac{2\left[\left(c_{0}-c_{1} H(t)\right) \beta-\alpha\right]}{N(2 \eta \sigma-1)}+\frac{4 V^{\prime}(H, t)(1-\gamma) \beta \eta \sigma}{N(2 \eta \sigma-1)^{2} S_{a}}\right\}
$$

Sustituting (11) and (19) in HJB, and rearranging the terms, it follows:

$$
\begin{aligned}
r V(H, t)= & \frac{2 \eta^{2} \sigma^{2} \beta(1-\gamma)^{2}}{S_{a}^{2}(2 \eta \sigma-1)^{2}} \cdot\left(V^{\prime}(H, t)\right)^{2}+ \\
& +\frac{2 \eta \sigma(1-\gamma)\left[\beta\left(c_{0}-c_{1} H(t)\right)-\alpha\right]-(2 \eta \sigma-1)(\delta H(t)-R-\Omega)}{S_{a}(2 \eta \sigma-1)} \cdot\left(V^{\prime}(H, t)\right) \\
& +\frac{\left[\beta\left(c_{0}-c_{1} H(t)\right)-\alpha\right]^{2}}{2 \beta}-d_{0}+d_{1} H(t)
\end{aligned}
$$

As the game is of the linear-quadratic variety, we postulate a quadratic function of the form:

$$
V(H, t)=A H^{2}(t)+B H(t)+C
$$

with first derivative:

$$
V^{\prime}(H, t)=2 A H(t)+B
$$

where $A, B$ and $C$ are constant parameters of the unknown value function which are to be determined. Substituting the equations $V(H, t)$ and $V^{\prime}(H, t)$ in the HJB, we obtain a system of three Riccati equations for the coefficients of the value function:

$$
\begin{aligned}
r A= & \frac{8 \eta^{2} \sigma^{2} \beta(1-\gamma)^{2}}{(2 \eta \sigma-1) S_{a}^{2}} A^{2}-\frac{2\left[\delta(2 \eta \sigma-1)+2 \eta \sigma c_{1} \beta(1-\gamma)\right]}{S_{a}(2 \eta \sigma-1)} A+\frac{\beta c_{1}^{2}}{2} \\
r B= & \frac{8 \eta^{2} \sigma^{2} \beta(1-\gamma)^{2}}{S_{a}^{2}(2 \eta \sigma-1)^{2}} A B+\frac{2(R+\Omega)(2 \eta \sigma-1)+4 \eta \sigma(1-\gamma)\left(c_{0} \beta-\alpha\right)}{S_{a}(2 \eta \sigma-1)} A \\
& -\frac{\delta(2 \eta \sigma-1)+2 \beta c_{1} \eta \sigma(1-\gamma)}{S_{a}(2 \eta \sigma-1)} B-c_{1}\left(\beta c_{0}-\alpha\right)+d_{1} \\
r C= & \frac{2 \eta^{2} \sigma^{2} \beta(1-\gamma)^{2}}{S_{a}^{2}(2 \eta \sigma-1)^{2}} B^{2}+\frac{(R+\Omega)(2 \eta \sigma-1)-2 c_{0} \beta \eta \sigma(1-\gamma)}{S_{a}(2 \eta \sigma-1)} B+\frac{\left(\beta c_{0}-\alpha\right)^{2}}{2 \beta}-d_{0}
\end{aligned}
$$

Equation (20) admits two real and distinct solutions:

$$
A_{1,2}=\frac{(2 \eta \sigma-1) S_{a}\left[\left(r S_{a}+2 \delta\right)(2 \eta \sigma-1)+4 c_{1} \eta \beta \sigma(1-\gamma) \pm \sqrt{D}\right]}{16 \beta \sigma^{2} \eta^{2}(1-\gamma)^{2}}
$$

where

$$
D=(2 \eta \sigma-1)\left(S_{a} r+2 \delta\right)\left[8 \eta \sigma \beta c_{1}(1-\gamma)+\left(r S_{a}+2 \delta\right)(2 \eta \sigma-1)\right]
$$

is always positive. Moreover, the solution has to satisfy the stability condition $\frac{d \dot{H}}{d H}<0$. Substituting (19) in the dynamics of the water table (4), and considering that $V^{\prime}(H, t)=$ $2 A H(t)+B$, the stability condition becomes:

$$
\frac{d \dot{H}}{d H}<0 \Longleftrightarrow-\frac{1}{S_{a}}\left\{\frac{\sigma \beta \eta(1-\gamma)\left[2 c_{1} S_{a}(2 \eta \sigma-1)-8 A(1-\gamma) \eta \sigma\right]}{S_{a}(2 \eta \sigma-1)^{2}}+\delta\right\}<0
$$


that is satisfied by the solution

$$
A_{1}=\frac{(2 \eta \sigma-1) S_{a}\left[\left(r S_{a}+2 \delta\right)(2 \eta \sigma-1)+4 c_{1} \eta \beta \sigma(1-\gamma)-\sqrt{D}\right]}{16 \beta \sigma^{2} \eta^{2}(1-\gamma)^{2}}
$$

which is a positive constant. Moreover, from equation (21), we determine the value of $B=B_{1}$ as:

$$
B_{1}=\frac{(2 \eta \sigma-1) S_{a}\left\{2(2 \eta \sigma-1) A_{1}(R+\Omega)+4 A_{1}(1-\gamma)\left(\beta c_{0}-\alpha\right) \eta \sigma-(2 \eta \sigma-1) S_{a}\left[c_{1}\left(\beta c_{0}-\alpha\right)-d_{1}\right]\right\}}{S_{a}(2 \eta \sigma-1)^{2}\left(\delta+r S_{a}\right)+\beta \eta \sigma(1-\gamma)\left[2 c_{1} S_{a}(2 \eta \sigma-1)-8 A_{1}(1-\gamma) \eta \sigma\right]}
$$

Finally,

$$
\begin{aligned}
\tau^{*}= & \frac{8 \eta \sigma}{(4 \eta \sigma-1) S_{a}(2 \eta \sigma-1)^{2}}\left\{4\left[A_{1}(1-\gamma) \sigma^{2} \eta^{2}-\left(\frac{2 \eta \sigma-1}{8}\right) c_{1} S_{a}\right] H(t)\right. \\
& \left.+2 B_{1}(1-\gamma) \sigma^{2} \eta^{2}+\left(\beta c_{0}-\alpha\right) S_{a} \frac{(2 \eta \sigma-1)}{2 \beta}\right\}
\end{aligned}
$$

and

$$
\begin{aligned}
w^{*}= & \frac{4 \eta \sigma}{N(2 \eta \sigma-1)^{2} S_{a}}\left\{\beta\left[c_{1}(2 \eta \sigma-1) \frac{S_{a}}{2}-2 \eta \sigma A_{1}(1-\gamma)\right] H(t)-\left[\eta \sigma \beta B_{1}(1-\gamma)\right.\right. \\
& \left.\left.+\frac{S_{a}}{2}\left(\beta c_{0}-\alpha\right)(2 \eta \sigma-1)\right]\right\}
\end{aligned}
$$

\section{Proof of Proposition 3}

Substituting the value of $w^{*}$ given by (25) in the water table dynamics (4) we get:

$$
\dot{H}=\widehat{Y} H+Y
$$

that is a linear differential equation in which the constants $Y$ and $\widehat{Y}$ are given by Eqs. (14) and (15), respectively, and depend on the parameters of the model. In particular, $\widehat{Y}$ is negative since it coincides with the stability condition $\frac{d \dot{H}}{d H}<0$ (see (23)). Solving Eq. (26) we obtain the trajectory (16) where $H^{*}$ is the steady-state value.

\section{References}

1. Arguedas C (2013) Pollution standards, technology investment and fines for non-compliance. J Regul Econ 44(2):156-176

2. Biancardi, M., Iannucci, G., Villani, G., 2021. An evolutionary game on compliant and non-compliant firms in groundwater exploitation. Ann Oper Res, 1-17

3. Biancardi M, Maddalena L (2018) Competition and cooperation in the exploitation of the groundwater resource. Decisions Econ Finan 41(2):219-237

4. Biancardi M, Maddalena L, Villani G (2020) Groundwater extraction among overlapping generations: a differential game approach. Decisions Econ Finan 43(2):539-556

5. Biancardi M, Maddalena L, Villani G (2020) Water taxes and fines imposed on legal and illegal firms exploiting groudwater. Discr Continuous Dyn Syst-B 22(11):1-20

6. Budds J (2009) Contested H2O: science, policy and politics in water resources management in Chile. Geoforum 40(3):418-430

7. Castellano I (2020) Water scarcity in the American west. Palgrave MacMillan, Springer Nature, Cham, Switzerland

8. Chavez C, Salgado H (2005) Individual transferable quota markets under illegal fishing. Environ Resource Econ 31(3):303-324 
9. de Frutos Cachorro J, Erdlenbruch K, Tidball M (2014) Optimal adaptation strategies to face shocks on groundwater resources. J Econ Dyn Control 40:134-153

10. De Stefano L, Lopez-Gunn E (2012) Unauthorized groundwater use: institutional, social and ethical considerations. Water Policy 14(S1):147-160

11. Erdlenbruch K, Tidball M, Zaccour G (2014) Quantity-quality management of a groundwater resource by a water agency. Environ Sci Policy 44:201-214

12. Esteban E, Albiac J (2011) Groundwater and ecosystems damages: questioning the Gisser-Sánchez effect. Ecol Econ 70(11):2062-2069

13. Esteban E, Dinar A (2013) Cooperative management of groundwater resources in the presence of environmental externalities. Environ Resource Econ 54(3):443-469

14. Gisser M, Sanchez DA (1980) Competition versus optimal control in groundwater pumping. Water Resour Res 16(4):638-642

15. Hatcher A (2014) Implications of a discard ban in multispecies quota fisheries. Environ Resource Econ 58(3):463-472

16. Koundouri P (2004) Current issues in the economics of groundwater resource management. J Econom Surv 18(5):703-740

17. Martínez-Santos P, Llamas MR, Martínez-Alfaro PE (2008) Vulnerability assessment of groundwater resources: a modelling-based approach to the Mancha Occidental aquifer Spain. Environ Modell Softw 23(9):1145-1162

18. Negri DH (1989) The common property aquifer as a differential game. Water Resour Res 25(1):9-15

19. Pereau J-C (2020) Conflicting objectives in groundwater management. Water Resour Econom 31:100122

20. Pereau J-C, Mouysset L, Doyen L (2018) Groundwater management in a food security context. Environ Resource Econ 71(2):319-336

21. Pereau J-C, Pryet A (2018) Environmental flows in hydro-economic models. Hydrogeol J 26(7):22052212

22. Pereau J-C, Pryet A, Rambonilaza T (2019) Optimality versus viability in groundwater management with environmental flows. Ecol Econ 161:109-120

23. Provencher B, Burt O (1993) The externalities associated with the common property exploitation of groundwater. J Environ Econ Manag 24(2):139-158

24. Roseta-Palma C (2003) Joint quantity/quality management of groundwater. Environ Resource Econ 26(1):89-106

25. Rubio SJ, Casino B (2001) Competitive versus efficient extraction of a common property resource: the groundwater case. J Econ Dyn Control 25(8):1117-1137

26. Rubio SJ, Casino B (2003) Strategic behavior and efficiency in the common property extraction of groundwater. Environ Resource Econ 26(1):73-87

27. Stranlund JK (2007) The regulatory choice of noncompliance in emissions trading programs. Environ Resource Econ 38(1):99-117

28. Van Long N (2011) Dynamic games in the economics of natural resources: a survey. Dyn Games Appl 1(1):115-148

29. Villegas-Palacio C, Coria J (2010) On the interaction between imperfect compliance and technology adoption: taxes versus tradable emissions permits. J Regul Econ 38(3):274-291

Publisher's Note Springer Nature remains neutral with regard to jurisdictional claims in published maps and institutional affiliations. 